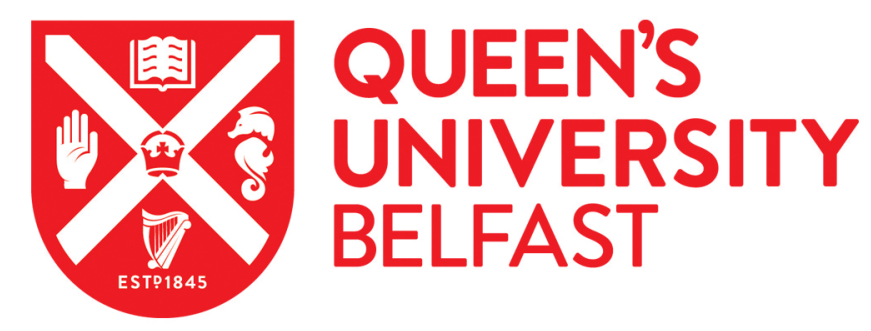

\title{
Lack of prey switching and strong preference for mosquito prey by a temporary pond specialist predator
}

Cuthbert, R. N., Dalu, T., Wasserman, R. J., Weyl, O. L. F., Froneman, P. W., Callaghan, A., \& Dick, J. T. A. (2019). Lack of prey switching and strong preference for mosquito prey by a temporary pond specialist predator. Ecological Entomology. https://doi.org/10.1111/een.12801

Published in:

Ecological Entomology

Document Version:

Peer reviewed version

Queen's University Belfast - Research Portal:

Link to publication record in Queen's University Belfast Research Portal

Publisher rights

(c) 2019 The Royal Entomological Society. This work is made available online in accordance with the publisher's policies. Please refer to any applicable terms of use of the publisher.

\section{General rights}

Copyright for the publications made accessible via the Queen's University Belfast Research Portal is retained by the author(s) and / or other copyright owners and it is a condition of accessing these publications that users recognise and abide by the legal requirements associated with these rights.

Take down policy

The Research Portal is Queen's institutional repository that provides access to Queen's research output. Every effort has been made to ensure that content in the Research Portal does not infringe any person's rights, or applicable UK laws. If you discover content in the Research Portal that you believe breaches copyright or violates any law, please contact openaccess@qub.ac.uk. 

specialist predator

5 Ross N. Cuthbert ${ }^{1,2,3, *}$, Tatenda Dalu ${ }^{4,5}$, Ryan J. Wasserman ${ }^{6,5}$, Olaf L. F. Weyl ${ }^{2}$, P.

6 William Froneman ${ }^{7}$, Amanda Callaghan ${ }^{3}$, Jaimie T. A. Dick ${ }^{1}$

$8 \quad{ }^{1}$ Institute for Global Food Security, School of Biological Sciences, Queen's University 9 Belfast, Belfast BT9 5DL, Northern Ireland

$10 \quad{ }^{2}$ DST/NRF Research Chair in Inland Fisheries and Freshwater Ecology, South African

11 Institute for Aquatic Biodiversity, Makhanda 6140, South Africa

$12{ }^{3}$ Ecology and Evolutionary Biology, School of Biological Sciences, University of Reading,

13 Harborne Building, Reading RG6 6AS, England

$14 \quad{ }^{4}$ Department of Ecology and Resource Management, University of Venda, Thohoyandou 0950, South Africa

${ }^{5}$ South African Institute for Aquatic Biodiversity, Makhanda 6140, South Africa

$17{ }^{6}$ Department of Biological Sciences and Biotechnology, Botswana International University of Science and Technology, Palapye, Botswana

${ }^{7}$ Department of Zoology and Entomology, Rhodes University, Makhanda 6140, South Africa

21 *Corresponding author: email, rcuthbert03@qub.ac.uk, tel: +44 2842728230 


\section{Abstract}

1. The strengths of trophic interactions within ecosystems can be mediated by complex mechanisms that require elucidation if we are to understand and predict population- and community-level stabilities. Where multiple prey types co-occur, prey switching (i.e. frequency-dependent predation) by predators may facilitate low prey density refuge effects which promote coexistence. On the other hand, lack of switching and strong preferences by predators can strongly suppress prey populations, which is especially important considering vector species such as mosquitoes.

2. In the present study, we quantify prey switching and preference patterns of the temporary pond specialist copepod Lovenula raynerae towards larvae of the medically important Culex pipiens mosquito complex in the presence of different proportions of alternative Daphnia pulex prey. Further, we examine whether prey switching and preferences are contingent on the sex of the predator.

\section{Lovenula raynerae exhibited a lack of prey switching and strong preference of larval} mosquito prey overall, irrespective of predator sex. Also, when larval mosquitoes were available in higher proportions over daphniids, the strength of this positive selectivity increased. There was very little low-density refuge for mosquitoes where they were rare.

\section{Lack of prey switching and strong preferences towards mosquitoes by predatory} paradiaptomid copepods may enhance population-level regulation of disease vector mosquitoes that exploit temporary pond-style habitats. Accordingly, the conservation and promotion of these predators may enable better management of medically important species across landscapes. 


\section{$46 \quad$ Key words}

47 Prey switching; preference; trophic interaction strength; ephemeral wetland; Culex pipiens; Lovenula raynerae

\section{Introduction}

51 Predation significantly influences the structure of populations and communities within ecosystems (Paine 1980; Sih et al. 1985). Whilst pairwise predator-prey interaction strengths are frequently used in inferences of community dynamics (Tang et al., 2014; Vázquez et al., 2015; Cuthbert et al., 2018c), patterns of prey selectivity are often ignored, despite their capacity to alter predation pressure towards single species (Murdoch, 1969; Cuthbert et al. 2018d). In particular, prey switching (i.e. frequency-dependent predation) can have significant implications for the stability of prey populations (Murdoch, 1969). That is, through avoidance of rare prey and disproportionate consumption of abundant prey (Fig. 1), switching behaviour may facilitate stability in population and community co-existence patterns, empirically aligned with type III sigmoidal functional response curves (Croy and Hughes, 1993). Accordingly, high prey switching propensities may reduce the strength of biotic resistance towards particular species (Cuthbert et al. 2018d), while lack of prey switching may suppress favoured prey species, with implications for regulation of important groups, such as medically important mosquitoes (Cuthbert et al. 2018a).

Ephemeral aquatic ecosystems are characterised by atypical trophic structuring, with community dynamics contingent on patterns of internal recruitment (i.e. resting egg hatching) and external recruitment via colonisation from other environments during wet phases (Brendonck and De Meester, 2003; Wasserman et al. 2016, 2018). In these habitats, top-down pressure is often driven by predaceous crustaceans which hatch from egg banks at the start of 
the wet phase (Wasserman et al. 2016). Higher-order insect predators (e.g. notonectids) are typically externally recruited much later (Wasserman et al. 2018), and thus predation pressure in these systems is transient, with implications for invertebrate community dynamics.

Mosquitoes successfully colonise different forms of temporary aquatic habitats via aerial dispersal and, by certain genera, oviposition of desiccation-resistant eggs (Tsurim et al. 2013; Townroe and Callaghan 2014). Whilst predatory temporary pond specialists have been recently identified as potentially important natural predators of vector mosquitoes that exploit ephemeral aquatic habitats (Cuthbert et al. 2018b), it is unknown how alternative prey types, which are also recruited into these ecosystems, alter interaction strengths towards mosquitoes. In particular, daphniid prey are often numerically dominant pioneering crustaceans in temporary ponds (Wasserman et al. 2016), and their presence may therefore regulate predation pressure towards mosquitoes where they coexist.

In the present study, we examine the prey switching and preferences of the specialist predatory calanoid copepod Lovenula raynerae (Calanoida: Diaptomidae) between larvae of the Culex pipiens (Diptera: Culicidae) mosquito complex and alternative daphniid prey. Lovenula raynerae is endemic to South Africa and is often numerically dominant in its native range, with larval mosquitoes and daphniids comprising important components of their diet (Wasserman et al. 2016; Cuthbert et al. 2019). We compare predatory behaviour of male and female copepods as sex ratios in temporary ponds are known to become sex-skewed over time (Wasserman et al. 2018). Interaction strengths and resource specialisation are also known to vary according to sex and reproductive status in these systems (Dalu et al. 2017; Cuthbert et al. 2019). Therefore, prey selectivity patterns may differ between sexes, resulting in changes to predator-prey dynamics over the hydroperiod. 
95

The predator L. raynerae was collected from an ephemeral pond in the Eastern Cape Province of South Africa ( $\left.33^{\circ} 15^{\prime} 04.0^{\prime \prime S} 26^{\circ} 26^{\prime} 16.4^{\prime \prime E}\right)$ by hauling a $64 \mu \mathrm{m}$ mesh zooplankton net through the water column. These copepods were transported in source water to a controlled environment (CE) room in the Department of Zoology and Entomology, Rhodes University, Makhanda (Grahamstown), maintained at $25 \pm 2{ }^{\circ} \mathrm{C}$ and under a 14:10 light:dark regime. In the CE room, adult male and female copepods were separately starved in $5 \mathrm{~L}$ aquaria containing $100 \mu \mathrm{m}$ filtered water from the source pond for 24 hours prior to the experiment. Daphnia pulex (Cladocera: Daphniidae) group were collected from a permanent waterbody using a zooplankton net, as before $\left(33^{\circ} 18^{\prime} 33.9^{\prime \prime S} 26^{\circ} 30^{\prime} 03.1^{\prime \prime E}\right)$. Larval C. pipiens complex mosquitoes were cultured from egg rafts collected from artificial containers on the university campus in the CE room, and fed ad libitum with ground guinea pig food pellets (Agricol, Port Elizabeth).

The two prey types (C. pipiens, $3-5 \mathrm{~mm}$; D. pulex $1-2 \mathrm{~mm})$ were introduced simultaneously into glass experimental arenas of $5.6 \mathrm{~cm}$ diameter containing $50 \mathrm{~mL}$ filtered source water. Prey were introduced under five different ratios (C. pipiens:D. pulex: 2:18, $5: 15,10: 10,15: 5,18: 2)$. After prey had settled for 3 hours in experimental arenas, either a single male or female L. raynerae was introduced and allowed to feed for 18 hours (i.e. 8:10 light:dark). Four replicates were undertaken for each prey ratio and predator sex, and controls consisted of three replicates at each prey ratio in the absence of predators to quantify background mortality resulting from factors other than predation. After the experimental period, predators were removed and remaining live prey counted to quantify mortality.

Statistical analyses were performed using R v3.5.1 (R Development Core Team, 2018). Generalised linear mixed effects models assuming a Poisson error distribution and log link 
were used to examine the number of individuals consumed with respect to prey species, predator sex and prey proportion and their two- and three-way interactions. Each independent variable was included as a categorical predictor in the model. A random effects structure was integrated, with each experimental arena treated as a random intercept to account for multiple measurements within individual arenas. An information theoretic approach was used to select the model with parameters which minimised information loss via AICc (Burnham and Anderson, 2002). Models with $\triangle \mathrm{AICc}<2$ were considered interchangeable. Analysis of deviance with type III sums of squares was used to infer significance levels. Manly's selectivity index, assuming non-replacement of prey, was applied to model prey preferences towards larval mosquitoes according to their environmental availability (Manly, 1972; Chesson, 1983):

$$
\alpha_{i}=\left(\ln \left(\left(n_{i 0}-r_{i}\right) / n_{i 0}\right)\right) / \sum_{j=1}^{m}\left(\ln \left(\left(n_{j 0}-r_{j}\right) / n_{j 0}\right)\right)
$$

where $a_{i}$ is Manly's selectivity index for prey type $i, n_{\mathrm{i} 0}$ is the number of prey type $i$ available at the start of the experiment, $r_{i}$ is the number of prey type $i$ consumed, $m$ the number of prey types, $n_{j 0}$ the number of prey type $j$ available at the start of the experiment and $r_{j}$ is the number of prey type $j$ consumed. In a two-prey system, $\alpha_{i}$ ranges from 0 to 1 , with 1 indicating complete preference, 0 indicating complete avoidance and 0.5 indicating neutral selectivity. To remove extremes prior to analysis, we transformed indices:

$$
a_{t}=\left(\alpha_{i}(n-1)+0.5\right) / n
$$

where $\alpha_{t}$ is the transformed output and $n$ is the sample size. Beta regression was used to analyse preferences towards mosquitoes according to predator sex and prey proportion, with AICc used in model selection (as before). Nested likelihood ratio tests were used to infer significance levels. 


\section{Results and Discussion}

144 Irrespective of sex, adult L. raynerae preferentially selected $C$. pipiens prey over D. pulex across the majority of proportional availabilities (Fig. 1). The prey species, predator sex and prey proportion terms were included in the top model. The 'prey species $\times$ predator sex' and 'prey species $\times$ prey proportion' interactions were also included. Culex pipiens were consumed significantly more than $D$. pulex overall $\left(\chi^{2}=5.71\right.$, $\left.\mathrm{df}=1, p=0.02\right)$, and prey consumption increased significantly as a given prey type was available in higher proportions $\left(\chi^{2}=85.16, \mathrm{df}=4, p<0.001\right)$. There was no significant difference in consumption between predator sexes $\left(\chi^{2}=2.87, \mathrm{df}=1, p=0.09\right)$, and significantly higher consumption towards larval mosquitoes was consistent between sexes and proportions owing to non-significant 'prey species $\times$ predator sex' $\left(\chi^{2}=3.12, \mathrm{df}=1, p=0.08\right)$ and 'prey species $\times$ prey proportion' $\left(\chi^{2}=8.86, \mathrm{df}=4, p=0.06\right)$ interaction terms. However, female preferences tended to be less marked than males, and preference differences between prey were generally highest under greater availabilities. Selectivity indices towards mosquito prey surpassed 0.5 at proportional availabilities exceeding 0.5 for both predator sexes, indicating selective preference towards mosquito prey at these densities (Fig. 2). The prey proportion term alone was retained in the top model, with preference indices increasing significantly where mosquitoes were available in higher proportions $\left(\chi^{2}=21.66, \mathrm{df}=4, p<0.001\right)$.

The temporary pond specialist copepod L. raynerae exhibited a lack of prey switching from, and strong preference for, C. pipiens mosquito prey when alternative D. pulex prey were available. Also, as larval mosquito prey proportions increased, positive selectivity for this prey type intensified, while there was very little low density refuge for the mosquito. 
sex ratios previously shown to differ temporally and alter interaction strengths in temporary ponds (Wasserman et al. 2018; Cuthbert et al. 2019). Given the documented development of sex-skewed demographics in favour of female copepods in these systems (Wasserman et al. 2018), similarities in prey preferences may facilitate sustained top-down pressure on larval mosquitoes irrespective of sex demographics over the hydroperiod. Indeed, predatory paradiaptomid copepods have been recently identified as important natural enemies for mosquitoes which vector pathogens and parasites (Cuthbert et al. 2018b). Whilst their interaction strengths have been examined under various context-dependencies (e.g. Cuthbert et al. 2019), there has hitherto been a lack of examination of prey switching and preferences in temporary pond biota. Patterns of prey selectivity in favour of larval mosquitoes may enhance the regulation of disease vector species which exploit these ephemeral ecosystems, whilst potentially alleviating predation pressure on specialist zooplankters, such as daphniids.

Although larval mosquito and daphniid prey represent important dietary components of $L$. raynerae (Wasserman et al. 2016; Cuthbert et al. 2019), the presence of other prey types in these systems may further alter prey selection propensities. However, pairwise prey preference examinations between common prey offers novel comparative insights into predator-prey dynamics in these atyptical ecosystems, where trophic structuring is relatively simplified during the early stages of the hydroperiod. Nevertheless, owing to the importance of prey switching for population-level stability (Murdoch 1969), even small low-density refuge effects for larval mosquito prey may allow for development to the adult stage in instances where larvae are rare. Such density-dependent variation in selectivity could be driven by changes in search image or feeding behaviour as a given prey type becomes more abundant (Begon et al. 2006), or through physical or behavioural differences among prey. Whilst this study presents the first quantification of prey switching patterns and prey preferences in arid temporary pond specialists, further investigation is required to elucidate 
the potential context-dependencies of switching behaviours, and lack thereof, within these highly dynamic temporary pond ecosystems.

\section{Acknowledgements}

This study was funded by the Department for the Economy, Northern Ireland. We thank Rhodes University for the provision of laboratory facilities. We acknowledge use of infrastructure and equipment provided by the South African Institute for Aquatic Biodiversity (SAIAB) Research Platform and the funding channelled through the National Research Foundation - SAIAB Institutional Support system. This study was partly funded by the National Research Foundation - South African Research Chairs Initiative of the Department of Science and Technology (Inland Fisheries and Freshwater Ecology, Grant No. 110507). The authors declare that they have no conflicts of interest.

\section{References}

Begon, M., Townsend, C.R. \& Harper, J.L. (2006) Ecology: From Individuals to Ecosystems. Blackwell Publishing, London.

Brendonck, L. \& De Meester, L. (2003) Egg banks in freshwater zooplankton: evolutionary and ecological archives in the sediment. Hydrobiologia, 491, 65-84.

Burnham, K.P. \& Anderson, D.R. (2002) Model selection and multimodel inference. A practical information-theoretic approach. Springer, New York.

Croy, M.I. \& Hughes, R.N. (1991) The role of learning and memory in the feeding behaviour of the fifteen-spined stickleback, Spinachia spinachia L. Animal Behaviour, 41, 149159. 
Chesson, J. (1983) The estimation and analysis of preference and its relationship to foraging models. Ecology, 64, 1297-1304.

Cuthbert, R.N., Callaghan, A. \& Dick, J.T.A. (2018a) The effect of the alternative prey, Paramecium caudatum (Peniculida: Parameciidae), on the Predation of Culex pipiens (Diptera: Culicidae) by the copepods Macrocyclops albidus and Megacyclops viridis (Cyclopoida: Cyclopidae). Journal of Medical Entomology, 56, 276-279.

Cuthbert, R.N., Dalu, T., Wasserman, R.J., Callaghan, A., Weyl, O.L.F. \& Dick, J.T.A. (2018b) Calanoid copepods: an overlooked tool in the control of disease vector mosquitoes. Journal of Medical Entomology, 25, 1656-1658.

Cuthbert, R.N., Dick, J.T.A., Callaghan, A. \& Dickey, J.W.E. (2018c) Biological control agent selection under environmental change using functional responses, abundances and fecundities; the Relative Control Potential (RCP) metric. Biological Control, 121, $50-57$.

Cuthbert, R.N., Dickey, J.W.E., Laverty, C., McMorrow, C. \& Dick, J.T.A. (2018d) Resistance is futile: lack of predator switching and a preference for native prey predict the success of an invasive prey species. Royal Society Open Science, 5, 180339.

Cuthbert, R.N., Dalu, T., Wasserman, R.J., Weyl, O.L.F., Callaghan, A., Froneman, P.W. \& Dick, J.T.A. (2019) Sex-skewed trophic impacts in ephemeral wetlands. Freshwater Biology, 64, 359-366.

Dalu, T., Wasserman, R.J., Vink, T.J.F. \& Weyl, O.L.F. (2017) Sex and species specific isotopic niche specialisation increases with trophic complexity: evidence from an ephemeral pond ecosystem. Scientific Reports, 7, 43229. 
Manly, B.F.J. (1974) A model for certain types of selection experiments. Biometrics, 30, $281-294$

Murdoch, W.W. (1969) Switching in general predators: experiments on predator specificity and stability of prey populations. Ecological Monographs, 39, 335-354.

Paine, R.T. (1980) Food webs: linkage, interaction strength and community infrastructure. Journal of Animal Ecology, 49, 666-685.

R Development Core Team. (2018) R: a language and environment for statistical computing.

Sih, A., Crowley, P., McPeek, M., Petranka, J., \& Strohmeier, K. (1985) Predation, competition and prey communities: a review of field experiments. Annual Review of Ecology, Evolution, and Systematics. 16, 269-311.

Tang, S., Pawar, S. \& Allesina, S. (2014) Correlation between interaction strengths drives stability in large ecological networks. Ecology Letters, 17, 1094-1100.

Townroe, S. \& Callaghan, A. (2014) British container breeding mosquitoes: the impact of urbanisation and climate change on community composition and phenology. PLoS One, 9, e95325.

Tsurim, I., Silberbush, A., Ovadia, O., Blaustein, L. \& Margalith, Y. (2013) Inter- and intraspecific density-dependent effects on life history and development strategies of larval mosquitoes. PLoS One, 8, e57875.

Vázquez, D.P., Ramos-Jiliberto, R., Urbani, P. \& Valdovinos, F.S. (2015) A conceptual framework for studying the strength of plant-animal mutualistic interactions. Ecology Letters, 18, 385-400. 
257

258

259

260

261

262

263

264

265

266

267

268

269

270

271

272

273

274

275

276

Wasserman, R.J., Alexander, M.E., Barrios-O’Neill, D., Weyl, O.L.F., \& Dalu, T. (2016) Using functional responses to assess predator hatching phenology implications for pioneering prey in arid temporary pools. Journal of Plankton Research, 38, 154-158.

Wasserman, R.J., Weston, M., Weyl, O.L.F., Froneman, P.W., Welch, R.J., Vink, T.J.F. \& Dalu, T. (2018) Sacrificial males: the potential role of copulation and predation in contributing to copepod sex-skewed ratios. Oikos, 127, 970-980.

\section{3}

64

5

66

267

8 
277 Fig. 1. Proportion of mosquito and daphniid prey in diet of adult (a) male and (b) female

278 Lovenula raynerae across different proportional prey availabilities. Means are \pm 1 SE. The

279 solid line indicates the expected values under neutral selectivity. The dashed line represents a

280 hypothetical switching pattern. Note that the $x$-axis corresponds to proportional availability of

281 both prey types for comparative purposes.

282

283 Fig. 2. Manly’s selectivity indices towards larval mosquito prey by male and female

284 Lovenula raynerae across different proportional availabilities. Means are $+1 \mathrm{SE}$. The dashed

285 line indicated expected values under neutral selectivity. 